\title{
Girls-Day 2008 in der djb-Geschäftsstelle
}

„Wie wird man Anwältin?“, „Tragen Richterinnen Perücken?“ und „Was heißt eigentlich juristisch?“ - solchen und ähnlichen Fragen hat sich unser Berliner djb-Landesvorstandsmitglied Dr. Esther Hartwich am 24. April 2008 im Rahmen des Girls-Day gestellt.

Wie schon im Jahr 2007 besuchten neun Mädchen zwischen elf und 14 Jahren die djb-Geschäftsstelle, um sich über juristische Berufe zu informieBereiche aufgezeigt, in denen Juristinnen tätig sind. Waren den Mädchen insbesondere die klassischen Berufe der Anwältin, Richterin und Staatsanwältin bekannt, so waren ihnen die möglichen Tätigkeitsren. Spielerisch wurden ihnen die verschiedenen

felder in der Verwaltung und der Wirtschaft sowie bei Verbänden und Medien neu.

Als formale Bedingungen für die Berufe waren den Schülerinnen die Voraussetzungen eines guten Abiturs und Studiums bekannt, das Referendariat hingegen bedurfte einer genaueren Erklärung. Die beiden wichtigsten persönlichen Voraussetzungen für den Beruf der Juristin waren nach Ansicht der Mädchen Gerechtigkeitssinn und Unbestechlichkeit.

Die djb-Geschäftsstelle hat sich über das große Interesse seitens der Gruppe gefreut und will auch im nächsten Jahr wieder beim Girls-Day dabei sein!

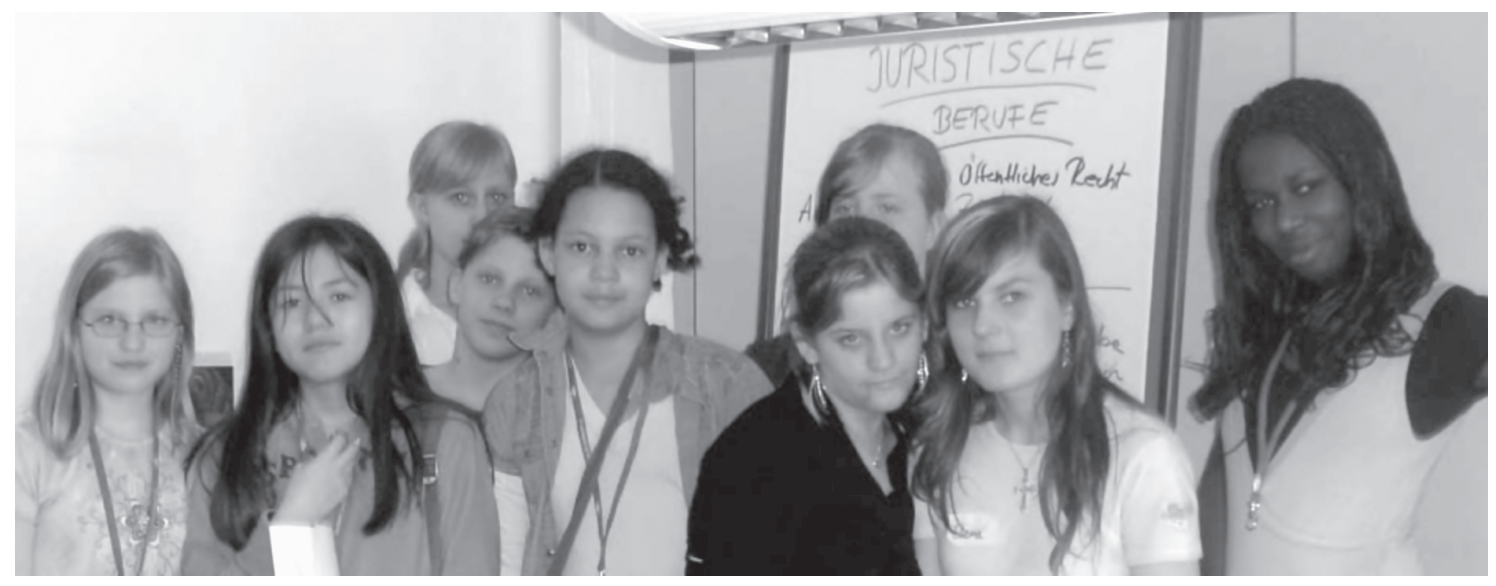

\section{Dr. Esther Hartwich}

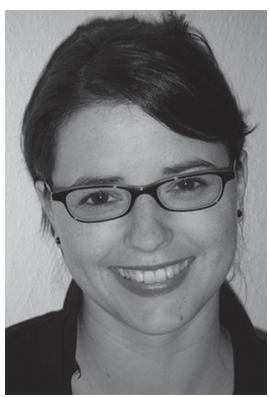

Mitglied im Vorstand des Landesverbandes Berlin des djb; Rechtsassessorin, Berlin

\section{Einladung}

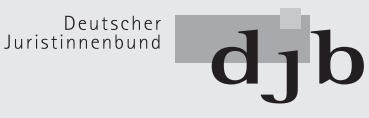

\author{
Der DEUTSCHE JURISTINNENBUND \\ bittet seine Mitglieder anlässlich des 67. Deutschen Juristentages in Erfurt \\ zu einem Empfang am \\ Mittwoch, dem 24. September 2008, von 18.30 bis 20.30 Uhr \\ im Coelicum des Mariendoms*. \\ Jutta Wagner \\ Präsidentin \\ Renate Maltry \\ Ramona Pisal \\ Vizepräsidentinnen \\ * Das Coelicum ist zu erreichen über den Treppenaufgang zum Dom St. Marien am Erfurter Domplatz. \\ Bitte bringen Sie diese Einladung am Abend der Veranstaltung als Einlasskarte mit.
}

